\title{
SURVEI INDEKS PERSEPSI KORUPSI DAN KEPUASAN LAYANAN BALAI LITBANG AGAMA SEMARANG TAHUN 2020
}

\author{
Darwiyanto
}

Balai Diklat Keagamaan Semarang

darwi_wi@yahoo.co.id

DOI : http://doi.org/10.37730/edutrained.v5i1.123

Diterima: 22 Februari 2021 | Disetujui: 14 Juni 2021 | Dipublikasikan: 6 Juli 2021

\begin{abstract}
Abstrak
Survei Indeks Persepsi Korupsi dan Kepuasan Layanan merupakan bagian area perubahan yang penting dalam Pembangunan Zona Integritas. Penelitian ini bertujuan untuk mengetahui Indeks Persepsi Korupsi dan Kepuasan Layanan pada Balai Litbang Agama (BLA) Semarang Tahun 2020. Penelitian ini menggunakan metode survei terhadap 150 pengguna layanan yang diberikan oleh BLA Semarang. Subyek penelitian ini adalah para pengguna layanan BLA Semarang Bidang Pendidikan Agama dan Keagamaan, Bidang Bimas Agama dan Keagamaan serta Bidang Lektur Khazanah Agama dan Manajemen Organisasi. Data hasil survei kemudian diolah menggunakan statistik frekuensi sederhana dan dideskripsikan dengan grafik atau diagram dan narasi sederhana. Hasil penelitian ini diperoleh hasil indeks persepsi korupsi sebesar 3,27 skala 4 dan Indeks kepuasan layanan 3,18 skala 4. Berdasarkan hasil penelitian ini diharapkan Kepala BLA Semarang agar dapat memberikan bimbingan kepada pegawai BLA Semarang khususnya pada aspek layanan petugas dalam memberikan solusi masalah yang dihadapi pengguna.
\end{abstract}

Kata Kunci: indeks, kepuasan layanan, persepsi korupsi

\begin{abstract}
The Corruption Perception Index and Service Satisfaction Survey are part of an important area of change in the Integrity Zone Development. This study aims to determine the Corruption Perception Index of the Service Satisfaction at Office of Religious Research and Development, Semarang, Ministry of Religious Affairs in 2020. This study uses a survey method of 150 service users provided by the BLA Semarang. The subjects of this study were users of Religious Research and Development Semarang services in the field of religious education, the field of religious and religious guidance and the field of literature in the field of religion and organizational management. The survey data is processed using simple frequency statistics and described with simple graphs or diagrams and narrative. From the results of this study, the corruption perception index is 3.27 on a scale of 4 and a service satisfaction index of 3.18 on a scale of 4.Based on the results of this study, it is hoped that the Head of the Religious Research and Development can provide guidance to the Religious Research and Development employees, especially in the aspect of officer service in providing solutions to problems faced by users.
\end{abstract}

Keywords: Corruption Perception, Index, Service Satisfaction 


\section{PENDAHULUAN}

Korupsi merupakan penyakit birokrasi yang menghambat proses pelayanan dalam kehidupan berbangsa dan bernegara. Hal ini sangat menghambat proses dan hasil pembangunan secara nasional. Marwata menyampaikan, bahwa Indeks Persepsi Korupsi (IPK) Indonesia angkanya 40 dari skala 0-100. Untuk lingkup negara ASEAN, Indonesia di bawah Singapura dan Malaysia. Ini artinya gap dengan negara-negara lain masih jauh; negara lain angka rata-ratanya adalah 90 (Haryanto, 2020: 1). Berdasarkan data yang dirilis oleh Transparency International dalam Corruption Perception Index Indonesia memiliki skore 37 dari skala 100 dan menempati ranking ke 102 dari 180 negara.

Dalam rangka pembangunan Zona Integritas menuju Wilayah Bebas Korupsi, BLA Semarang memerlukan masukan dari masyarakat mengenai pelayanannya. Hal ini tercantum dalam Perjanjian Kinerja (Perkin) Kepala BLA Semarang tahun 2020 aspek peningkatan kualitas manajemen target nilai PMPZI adalah 85 (Badan Litbang dan Diklat, 2020). Hal ini menjadi tagihan yang harus dicapai dalam pembangunan Zona Integritas BLA Semarang sebagai UPT di Badan Litbang dan Diklat Kementerian Agama RI. Oleh karena itu, BLA Semarang dituntut dapat melakukan Reformasi Birokrasi dalam pelaksanaan layanan di Tahun 2020.

Reformasi birokrasi menuntut semua Aparatur Sipil Negara (ASN) di Kementerian/Lembaga memiliki integritas dalam melakukan peningkatan layanan yang signifikan dalam melaksanakan tugas pemerintahan. Perubahan yang harus dilakukan dalam pelaksanaan tugas sebagai ASN adalah menghilangkan perilaku korupsi demi meningkatkan layanan terhadap para pengguna layanan sehingga mereka merasa puas atas layanan yang diperoleh. Indeks persepsi korupsi dan kepuasan layanan merupakan salah satu indikator dalam Penilaian Mandiri Pembangunan Zona Integritas (PMPZI).

Dengan kondisi di atas maka penelitian dengan judul "Survei Indeks Persepsi
Korupsi dan Layanan Balai Litbang Agama Semarang Tahun 2020" dilakukan.

Penelitian ini dilakukan untuk menjawab masalah yang ada pada pelayanan yang dilakukan oleh BLA Semarang antara lain; 1). Seberapa besar penilaian masyarakat terhadap persepi korupsi dan kepuasan layanan yang diberikan oleh BLA Semarang?, 2) Aspek apa saja yang mempengaruhi indeks persepsi korupsi dan kepuasan layanan di BLA Semarang?, 3) Aspek apa yang mendapat nilai tertinggi dan nilai terendah dari indeks persepsi korupsi dan kepuasan layan di BLA semarang Tahun 2020.

Indeks Persepsi Korupsi dan Kepuasan Layanan merupakan salah satu area perubahan dalam membangun Zona Integritas. Penelitian ini bertujuan untuk mengetahui berapa besar indeks persepsi korupsi dan kepuasan layanan di BLA Semarang Tahun Anggaran 2020. Hasil penelitian ini diharapkan dapat memberikan kontribusi terhadap PMPZI BLA Semarang Tahun 2020. Selain itu penelitian ini juga diharapkan dapat bermanfaat sebagai masukan kepada Kepala BLA Semarang dalam merumuskan kebijakan selanjutnya dalam rangka pembinaan pegawai untuk membangun Zona Integritas menuju Wilayah Bebas Korupsi (WBK) - Wilayah Birokrasi Bersih Melayani (WBBM).

\section{KAJIAN PUSTAKA}

Dalam modul materi tindak pidana korupsi menyebutkan bahwa setiap orang yang dengan tujuan menguntungkan diri sendiri atau orang lain atau suatu korporasi, menyalahgunakan kewenangan, kesempatan atau sarana yang ada padanya karena jabatan atau kedudukan yang dapat merugikan keuangan negara atau perekonomian negara.

Menurut Haryanto (2020: 1) menyampaikan bahwa korupsi adalah segala bentuk penyalahgunaan wewenang untuk memperoleh manfaat pribadi. Korupsi dalam survei ini mengacu pada komponen layanan yang diselenggarakan oleh Balai Litbang Agama Semarang Tahun 2020. Persepsi adalah penafsiran dan 
penilaian seseorang terhadap fenomena sosial tertentu (Kementerian PAN \& RB: 17). Persepsi tidak hanya dihasilkan melalui penilaian subyektif yang cenderung personal, juga dihasilkan melalui penilaian obyektif bersumber dari pengalaman langsung atau tidak langsung dan/atau pengetahuan yang dimiliki oleh seseorang (International Transparency, 2016).

Pelayanan publik adalah kegiatan atau rangkaian kegiatan dalam rangka pemenuhan kebutuhan pelayanan sesuai dengan peraturan perundang - undangan bagi setiap warga negara dan penduduk atas barang, jasa, dan/atau pelayanan administratif yang disediakan oleh penyelenggara pelayanan publik (UU No. 25 2009 : 30)

Layanan menurut Kotler dan Keller (dalam Sasongko dan Subagio; 2013: 2) dijelaskan:

Satisfaction reflects a person's judgements of a product's perceived performance or outcome in relationship to expectation.

Sebagaimana dijelaskan bahwa Pelayanan Publik adalah kegiatan atau rangkaian kegiatan dalam rangka pemenuhan kebutuhan pelayanan sesuai dengan peraturan perundang-undangan bagi setiap warga negara dan penduduk atas barang, jasa, dan/atau pelayanan administratif yang disediakan oleh penyelenggara pelayanan publik (Manaf. A. 2016 : 27). Kepuasaan layanan mengandung perasaan puas terhadap produk layanan baik berupa layanan jasa maupun barang yang disampaikan oleh penerima layanan.

Mengacu pada pengertian tersebut, maka menurut penulis Indeks Persepsi Korupsi Layanan BLA Semarang adalah bagaimana persepsi pengguna layanan memiliki penilaian terhadap layanan barang dan jasa yang diberikan oleh BLA Semarang, yang dihubungkan dengan persepsi korupsi di BLA Semarang Tahun 2020.

Berdasarkan penilaian Zona Integritas yang ditetapkan oleh Menpan RB, Persepsi Korupsi dalam survei ini meliputi beberapa aspek, yaitu; (a) Persyaratan pelayanan; (b) Prosedur Pelayanan; (c) Waktu Pelayanan; (d) Biaya dan Tarif;
(e)Produk/Jasa Spesifikasi Jenis Layanan;(f) Kompetensi Petugas Pelaksana dan Keandalan Sistem; (g) Layanan Petugas Memberikan Solusi; dan (h) Penanganan Pengaduan, Saran, dan Masukan (Menpan RB. 2017: 30). Dengan memperhatikan aspek tersebut maka penelitian ini menggunakan instrumen yang dibuat oleh Menpan RB mencakup beberapa aspek sebagaimana yang disampaikan tersebut.

\section{METODE PENELITIAN}

Dalam penelitian ini responden yang dipilih adalah peserta seminar hasil penelitian selama periode semester 2 bulan Agustus sampai November 2020 di Provinsi Jawa Tengah dan DI Jogyakarta. Jumlah responden yang mengisi survei pelayanan publik yang disediakan adalah sebanyak 72 responden yang terdiri atas 25 responden layanan Bidang Lektur Khazanah Keagamaan dan Manajemen Organisasi (LKMMO); 23 responden layanan Bidang Pendidikan dan Keagamaan; dan 24 responden layanan Bidang Bimas Agama dan Layanan Keagamaan, Teknik pengambilan sampel pada penelitian ini menggunakan teknik purposive sampling yaitu teknik pengambilan sampel dimana sampel dipilih berdasarkan pertimbangan tujuan penelitian (Nasution, 2011: 98). Metode penelitian ini menggunakan metode survei dengan instrumenberupa angket Indeks Persepsi Korupsi dan Kepuasan Layanan yang diterbitkan oleh Menpan RB. Survei kepuasan masyarakat terhadap layanan BLA Semarang Tahun 2020 dilaksanakan dengan 150 responden para peserta seminar hasil penelitian dan uji validasi kegiatan pengembangan. Para responden tersebut telah mengikuti salah satu bentuk pelayanan oleh BLA Semarang, yaitu berupa diseminasi kegiatan penelitian melalui rangkaian kegiatan pengembangan yang berupa uji validasi. Para responden berasal dari berbagai daerah di wilayah kerja BLA Semarang, antara lain: Kabupaten/Kota khususnya di wilayah Provinsi Jawa Tengah dan DI Yogyakarta. Bervariasinya daerah responden dikarenakan dengan format kegiatan yang 
bisa dijangkau oleh banyak peserta dari berbagai daerah.

Tanggapan Responden terhadap Kategori Indeks Persepsi Korupsi dan Layanan terdapat 8 kategori unsur Indeks Persepsi Korupsi dalam survei ini, yaitu: (A) Persyaratan pelayanan; (B) Prosedur Pelayanan; (C) Waktu Pelayanan; (D) Biaya dan Tarif; (E) Produk/Jasa Spesifikasi Jenis Layanan; (F) Kompetensi Petugas Pelaksana dan Keandalan Sistem; (G) Layanan Petugas Memberikan Solusi; dan (H) Penanganan Pengaduan, Saran, dan Masukan.

Data hasil survei kemudian diolah menggunakan statistic frekuensi sederhana disajikan dalam tabel dan dideskripsikan dengan grafik serta narasi sederhana (Nazir ,2003: 381). Penggambaran angka/bilangan atau penyajian data angka tersebut dapat disajikan dalam bentuk tabel atau grafik/gambar, yang kemudian dikenal dengan istilah tabel distribusi frekuensi dan grafik distribusi frekuensi (Setiawan P, 2020: 1). Distribusi jawaban responden terhadap instrumen menggambarkan variabel yang dilambangkan dengan prosentase/angka yang telah terbagi dan tersebar sebagaimana dalam hasil penelitian ini.

Data persepsi diukur dengan menggunakan skala penilaian antara $1-4$. Nilai 1 merupakan skor persepsi paling rendah, dan nilai 4 merupakan skor persepsi paling tinggi dan mencerminkan kualitas birokrasi yang bersih dan baik dalam melayani (Menpan RB, 2017:17). Tingkat kualitas pelayanan di mulai dari sangat baik/puas sampai dengan tidak baik / tidak puas, pembagian jawaban dibagi dalam 4 (empat) kategori, yaitu: tidak baik, diberi nilai persepsi 1; kurang baik, diberi nilai persepsi 2; baik, diberi nilai 3; sangat baik, diberi nilai persepsi 4 (Menpan RB, 2017 : 16).

\section{HASIL PENELITIAN DAN PEMBAHASAN}

\section{Hasil Penelitian}

Berdasarkan hasil penghitungan angket yang telah diisi oleh responden diperoleh hasil sebagaimana dalam Tabel 1. sebagai berikut. 


\begin{tabular}{|c|c|c|c|c|c|}
\hline \multicolumn{6}{|l|}{ A :Persyaratan Pelayanan } \\
\hline Aspek & Sangat Mudah & Mudah & Sulit & Sangat Sulit & Tidak Menjawab \\
\hline 1. Informasi tentang Persyaratan Pelayanan. & $41,67 \%$ & $54,17 \%$ & $0 \%$ & $1,39 \%$ & $2,78 \%$ \\
\hline 2. Persyaratan Pelayanan yang Harus Disiapkan. & $34,72 \%$ & $61,11 \%$ & $1,39 \%$ & $0 \%$ & $2,78 \%$ \\
\hline \multicolumn{6}{|l|}{ B : Prosedur Pelayanan } \\
\hline 3. Informasi Alur Pelayanan. & $36,11 \%$ & $61,11 \%$ & $0 \%$ & $0 \%$ & $2,78 \%$ \\
\hline 4. Pemenuhan Prosedur/Alur Pelayanan. & $33,33 \%$ & $62,50 \%$ & $1,39 \%$ & $0 \%$ & $2,78 \%$ \\
\hline $\begin{array}{l}\text { 5. Sudah Memadai dan Tidak Berpotensi Menimbulkan } \\
\text { KKN }\end{array}$ & $45,83 \%$ & $50 \%$ & $0 \%$ & $0 \%$ & $4,17 \%$ \\
\hline $\begin{array}{l}\text { 6. Petugas Pelayanan Tidak memberikan pelayanan di Luar } \\
\text { Prosedur yang telah ditetapkan dengan imbalan } \\
\text { uang/barang. }\end{array}$ & $40,28 \%$ & $47,22 \%$ & $8,33 \%$ & $0 \%$ & $4,16 \%$ \\
\hline \multicolumn{6}{|l|}{ C: Waktu Pelayanan } \\
\hline 7. Informasi Waktu Pelayanan & $44,44 \%$ & $52,78 \%$ & $0 \%$ & $0 \%$ & $2,78 \%$ \\
\hline 8. Aspek Kesesuaian Pelayanan dengan Waktu operasional & $34,72 \%$ & $59,72 \%$ & $1,38 \%$ & $0 \%$ & $4,17 \%$ \\
\hline D : Biaya dan Tarif & Sangat Jelas & Jelas & $\begin{array}{l}\text { Kurang } \\
\text { Jelas }\end{array}$ & Tidak Jelas & Tidak Menjawab \\
\hline 9. Aspek Informasi tentang Biaya Pelayanan & $27,78 \%$ & $68,06 \%$ & $1,39 \%$ & $1,39 \%$ & $1,39 \%$ \\
\hline \multirow[t]{2}{*}{ 10. Terdapat Praktik Percaloan/ Perantara. } & Sangat Setuju & Setuju & $\begin{array}{l}\text { Kurang } \\
\text { Setuju }\end{array}$ & $\begin{array}{l}\text { Tidak } \\
\text { Setuju }\end{array}$ & Tidak Menjawab \\
\hline & $47,22 \%$ & $48,61 \%$ & $0 \%$ & $0 \%$ & $4,17 \%$ \\
\hline \multirow[t]{2}{*}{ 11. Aspek Tidak Terdapat Pungutan Liar. } & SangatSetuju & Setuju & $\begin{array}{l}\text { Kurang } \\
\text { Setuju }\end{array}$ & TidakSetuju & TidakMenjawab \\
\hline & $48,61 \%$ & $44,44 \%$ & $5,55 \%$ & $0 \%$ & $1,39 \%$ \\
\hline \multicolumn{6}{|l|}{ E: Produk/Jasa Spesifikasi Jenis Layanan } \\
\hline \multirow[t]{2}{*}{ 12. Informasitentang Daftar Produk/ JasaLayanan. } & SangatJelas & Jelas & $\begin{array}{l}\text { Kurang } \\
\text { Jelas }\end{array}$ & Tidak Jelas & Tidak Menjawab \\
\hline & 34,72 & 59,72 & $2,78 \%$ & $0 \%$ & $2,78 \%$ \\
\hline \multirow[t]{2}{*}{ 13. KemudahanAksesSeluruhProduk/Jasa Layanan. } & Sangat Mudah & Mudah & Sulit & Sangat Sulit & Tidak Menjawab \\
\hline & $40,28 \%$ & $55,55 \%$ & $0 \%$ & $0 \%$ & $4,17 \%$ \\
\hline
\end{tabular}




\begin{tabular}{|c|c|c|c|c|c|}
\hline \multicolumn{6}{|l|}{ F:KompetensiPetugasPelaksana dan KeandalanSistem } \\
\hline \multirow[t]{2}{*}{ 14. KompetensiPetugasPelayanan. } & $\begin{array}{c}\text { Sangat } \\
\text { Kompeten }\end{array}$ & $\begin{array}{c}\text { Kompete } \\
\mathrm{n}\end{array}$ & $\begin{array}{c}\text { Kurang } \\
\text { Kompeten }\end{array}$ & $\begin{array}{c}\text { Tidak } \\
\text { Kompeten }\end{array}$ & Tidak Menjawab \\
\hline & $41,67 \%$ & $55,55 \%$ & $0 \%$ & $0 \%$ & $2,78 \%$ \\
\hline \multirow[t]{2}{*}{ 15. PetugasPelayananBertanggungjawab. } & Sangat Setuju & Setuju & $\begin{array}{l}\text { Kurang } \\
\text { Setuju }\end{array}$ & $\begin{array}{l}\text { Tidak } \\
\text { Setuju }\end{array}$ & Tidak Menjawab \\
\hline & $45,83 \%$ & $51.39 \%$ & $0 \%$ & $0 \%$ & $5,55 \% \%$ \\
\hline \multirow[t]{2}{*}{ 16. KeandalanAplikasi/SistemPelayanan. } & Sangat Baik & Baik & Buruk & $\begin{array}{l}\text { Sangat } \\
\text { Buruk }\end{array}$ & Tidak Menjawab \\
\hline & $44,44 \%$ & $50,00 \%$ & $0 \%$ & $0 \%$ & $5,55 \%$ \\
\hline \multirow[t]{2}{*}{ 17. Petugas Pelayanan Tidak Diskriminatif. } & Sangat Setuju & Setuju & $\begin{array}{l}\text { Tidak } \\
\text { Setuju }\end{array}$ & $\begin{array}{c}\text { Sangat } \\
\text { Tidak } \\
\text { Setuju }\end{array}$ & Tidak Menjawab \\
\hline & $45,83 \%$ & $43,06 \%$ & $5,55 \%$ & $0 \%$ & $5,55 \%$ \\
\hline \multirow[t]{2}{*}{ 18. PetugasPelayananMenolakPemberian Uang/Barang. } & SangatSetuju & Setuju & $\begin{array}{c}\text { TidakSetuj } \\
\mathrm{u} \\
\end{array}$ & $\begin{array}{c}\text { SangatTida } \\
\text { kSetuju }\end{array}$ & TidakMenjawab \\
\hline & $45,83 \%$ & $43,06 \%$ & $5,55 \%$ & $0 \%$ & $5,55 \%$ \\
\hline
\end{tabular}

\section{G : Layanan Petugas Memberikan Solusi}

\begin{tabular}{|c|c|c|c|c|c|}
\hline \multirow[t]{2}{*}{ 19. Petugas Pelayanan Memberikan Solusi. } & $\begin{array}{c}\text { SangatPu } \\
\text { as } \\
\end{array}$ & Puas & $\begin{array}{c}\text { Kurang } \\
\text { Puas }\end{array}$ & $\begin{array}{l}\text { TidakPu } \\
\text { as }\end{array}$ & $\begin{array}{c}\text { TidakMenja } \\
\text { wab }\end{array}$ \\
\hline & $31,94 \%$ & $58,33 \%$ & $2,78 \%$ & $0 \%$ & $6,94 \%$ \\
\hline \multirow[t]{2}{*}{ 20. Kecepatan Petugas Pelayanan dalam Memberikan Solusi. } & $\begin{array}{c}\text { Sangat } \\
\text { Puas }\end{array}$ & Puas & $\begin{array}{c}\text { Kurang } \\
\text { Puas }\end{array}$ & $\begin{array}{l}\text { Tidak } \\
\text { Puas } \\
\end{array}$ & $\begin{array}{c}\text { TidakMenja } \\
\text { wab }\end{array}$ \\
\hline & $40,28 \%$ & $55,55 \%$ & $0 \%$ & $0 \%$ & $4,17 \%$ \\
\hline \multicolumn{6}{|l|}{ H : Penanganan Pengaduan, Saran, dan Masukan } \\
\hline \multirow[t]{2}{*}{ 21. Kemudahan Akses Fasilitas Pengaduan. } & $\begin{array}{l}\text { Sangat } \\
\text { Mudah }\end{array}$ & Mudah & Sulit & $\begin{array}{l}\text { SangatS } \\
\text { ulit }\end{array}$ & $\begin{array}{c}\text { TidakMenja } \\
\text { wab }\end{array}$ \\
\hline & $30,55 \%$ & $63,89 \%$ & $0 \%$ & $0 \%$ & $5,55 \%$ \\
\hline
\end{tabular}




\begin{tabular}{|c|c|c|c|c|c|}
\hline \multirow[t]{2}{*}{ 22. Prosedur Pengaduan Mudah Dilakukan. } & $\begin{array}{c}\text { SangatMu } \\
\text { dah }\end{array}$ & Mudah & Sulit & $\begin{array}{l}\text { SangatS } \\
\text { ulit }\end{array}$ & $\begin{array}{c}\text { TidakMenja } \\
\text { wab }\end{array}$ \\
\hline & 36,11 & 58,33 & $1,39 \%$ & $0 \%$ & $4,17 \%$ \\
\hline \multirow[t]{2}{*}{ 23. Petugas Pelayanan Pengaduan dapat Memberikan Solusi .( 72 responden) } & $\begin{array}{c}\text { SangatSet } \\
\text { uju }\end{array}$ & Setuju & $\begin{array}{c}\text { Kurang } \\
\text { Setuju }\end{array}$ & $\begin{array}{c}\text { Tidakset } \\
\text { uju }\end{array}$ & $\begin{array}{c}\text { TidakMenja } \\
\text { wab }\end{array}$ \\
\hline & $20,83 \%$ & $43,06 \%$ & $1,39 \%$ & $0 \%$ & $34,72 \%$ \\
\hline (47responden) & $31,91 \%$ & $65,95 \%$ & $2,13 \%$ & $0 \%$ & $0 \%$ \\
\hline \multirow[t]{2}{*}{ 24. Ada Kepastian Tindak Lanjut atas Penanganan Pengaduan. (72 responden) } & $\begin{array}{c}\text { SangatSet } \\
\text { uju }\end{array}$ & Setuju & $\begin{array}{c}\text { Kurang } \\
\text { Setuju }\end{array}$ & $\begin{array}{c}\text { Tidakset } \\
\text { uju }\end{array}$ & $\begin{array}{c}\text { TidakMenja } \\
\text { wab }\end{array}$ \\
\hline & $18,05 \%$ & $47,22 \%$ & $1,39 \%$ & $0 \%$ & $33,33 \%$ \\
\hline ( 48 responden ) & $27,08 \%$ & $70,83 \%$ & $2,08 \%$ & $0 \%$ & $0 \%$ \\
\hline \multirow[t]{2}{*}{ 25. Tidak Ada Diskriminasi dalam Penanganan pengaduan. (72 responden) } & $\begin{array}{c}\text { SangatSet } \\
\text { uju }\end{array}$ & Setuju & $\begin{array}{l}\text { Kurang } \\
\text { Setuju }\end{array}$ & $\begin{array}{c}\text { Tidakset } \\
\text { uju }\end{array}$ & $\begin{array}{c}\text { TidakMenja } \\
\text { wab }\end{array}$ \\
\hline & $23,61 \%$ & $27,78 \%$ & $0 \%$ & $0 \%$ & $48,61 \%$ \\
\hline ( 37 responden) & $45,95 \%$ & 54,05 & $0 \%$ & $0 \%$ & $0 \%$ \\
\hline \multirow[t]{3}{*}{$\begin{array}{l}\text { 26. Produk/Jasa Layanan yang Diterima Sesuai dengan Daftar ProdukJasa Layanan. (72 } \\
\text { responden dan } 37 \text { respondent) }\end{array}$} & $\begin{array}{l}\text { SangatSet } \\
\text { uju }\end{array}$ & Setuju & $\begin{array}{l}\text { Kurang } \\
\text { Setuju }\end{array}$ & $\begin{array}{l}\text { Tidakset } \\
\text { uju }\end{array}$ & $\begin{array}{l}\text { TidakMenja } \\
\text { wab }\end{array}$ \\
\hline & $23,61 \%$ & $27,77 \%$ & $0 \%$ & $0 \%$ & $48,61 \%$ \\
\hline & $45,94 \%$ & 54,05 & $0 \%$ & $0 \%$ & $0 \%$ \\
\hline
\end{tabular}


Berdasarkan Tabel 1 di atas dapat dijelaskan hasil survei Indeks Persepsi Korupsi dan Kepuasan Layanan BLA Semarang sebagai berikut;

Kategori A: Persyaratan Pelayanan.

Informasi tentang persyaratan pelayanan. Hampir $100 \%$ responden menyatakan informasi tentang persyaratan pelayanan mudah dan sangat mudah. Sebanyak $41,67 \%$ responden menyatakan sangat mudah dan sebanyak 54,17\% menyatakan mudah. Hampir $100 \%$ responden menyatakan pemenuhan dokumen persyaratan pelayanan yang harus disiapkan sangat mudah dan mudah, sejumlah $61,11 \%$ responden menyatakan mudah; dan $34,72 \%$ menyatakan sangat mudah.

Kategori B: ProsedurPelayanan.

Sejumlah $\quad 70$ responden $\quad(97,22 \%)$ menyatakan informasi alur pelayanan sangat mudah dan mudah. Tidak ada responden yang menyatakan sulit dan sangat sulit. Kemudian pemenuhan prosedur / alur pelayanan hampir 100\% responden menyatakan mudah dan sangat mudah terhadap aspek pemenuhan prosedur / alur pelayanan. Prosedur pelayanan yang ditetapkan sudah memadai dan tidak berpotensi menimbulkan Korupsi, Kolusi, dan Nepotisme (KKN). Tidak ada responden yang menyatakan tidak setuju dan sangat setuju terhadap aspek ini. Sebanyak 95,83\% responden menyatakan setuju dan sangat setuju terhadap aspek prosedur pelayanan yang ditetapkan sudah memadai dan tidak berpotensi menimbulkan KKN. Petugas pelayanan tidak memberikan pelayanan di luar prosedur yang telah ditetapkan dengan imbalan uang/barang. Hampir 90\% responden menyatakan setuju dan sangat setuju terhadap aspek petugas pelayanan tidak memberikan pelayanan di luar prosedur yang telah ditetapkan dengan imbalan uang/barang.

Kategori C: Waktu Pelayanan.

Hampir $100 \%$ responden menyatakan jelas dan sangat jelas terhadap aspek informasi waktu pelayanan. Pelayanan diberikan sesuai dengan Waktu Operasional yang ditetapkan lebih dari 90\% responden menyatakan sesuai dan sangat sesuai terhadap kesesuaian pelayanan dengan waktu operasional.

Kategori D: Biaya dan Tarif

Kategori Biaya dan Tarif ini terdiri atas 3 aspek yang diteliti, yaitu: aspek 7 yang terdapat dalam Instrumen I dan aspek II.3 dan II.35 yang terdapat dalam InstrumenI I. Lebih dari 95\% responden memberikan pernyataan sangat jelas dan jelas terhadap aspek informasi tentang biaya pelayanan. Lebih dari 95\% responden menyatakan setuju dan sangat setuju terhadap aspek tidak terdapat praktik percaloan/perantara. Tidak terdapat pungutan liar, hampir 95\% responden menyatakan setuju dan sangat setuju terhadap aspek tidak terdapat pungutan liar. Sejumlah $48 \%$ sangat setuju dan $44,44 \%$ setuju dengan aspek ini. Tidak ada responden yang tidak setuju terhadap aspek ini.

Kategori E: Produk/Jasa Spesikasi

Jenis layanan ini terdiri atas 2 aspek, yaitu aspek informasi tentang daftar produk/jasa layanan dan aspek kemudahan akses seluruh produk/jasa layanan. Informasi tentang Daftar Produk/Jasa Layanan. Berdasarkan Tabel bahwa hampir 95\% responden menyatakan jelas dan sangat jelas. Berdasarkan di atas, lebih dari 95\% responden menyatakan mudah dan sangat mudah.

Kategori F: Kompetensi Petugas Pelaksana dan Keandalan Sistem Mendekati 100\% responden yang menyatakan kompeten dan sangat kompeten terhadap aspek kompetensi petugas pelayanan. Hampir $100 \%$ responden memberikan tanggapan setuju dan sangat setuju. Hampir 95\% responden menyatakan baik dan sangat baik terhadap aspek keandalan apliaksi/sistem pelayanan. Sebesar 90\% responden menyataan setuju dan sangat setuju terhadap aspek petugas pelayanan tidak diskriminatif. Petugas pelayanan menolak pemberian uang/barang terkait dengan pelayanan yang diberikan. Jumlah tanggapan responden c kriteria sangat setuju dan setuju adalah hampir 90\%. Terdapat $4(5,55 \%)$ responden yang tidak setuju. Kategori G: Layanan Petugas Memberikan Solusi.

Layanan Petugas Memberikan Solusi terdiri atas 2 aspek, yaitu petugas pelayanan 
memberikan solusi kepada pengguna apabila ada permasalahan; dan aspek kecepatan petugas pelayanan dalam memberikan solusi permasalahan. Hampir 90\% responden menyatakan puas dan sangat puas terhadap aspek petugas pelayanan memberikan solusi. Lebih dari 95\% responden menyatakan puas dan sangat puas terhadap aspek kecepatan petugas pelayanan dalam memberikan solusi.

Kategori H: Penanganan Pengaduan, Saran, dan Masukan. Empat instrumen terakhir diisi oleh peserta yang pernah melakukan pengaduan. Lebih dari $90 \%$ responden menyatakan mudah dan sangat mudah pada aspek kemudahan akses fasilitas pengaduan. Hampir 95\% responden menyatakan aspek prosedur pengaduan di BLA Semarang mudah dan sangat mudah dilakukan. Petugas pelayanan pengaduan dapat memberikan solusi kepada pelapor apabila ada permasalahan. Dari sejumlah 47 responden yang menyatakan pernah melakukan pengaduan, hampir 100\% responden setuju dan sangat setuju terhadap aspek petugas pelayanan pengaduan dapat memberikan solusi .Ada kepastian tindak lanjut atas penanganan pengaduan. Dari sejumlah 48 responden yang menyatakan pernah melakukan pengaduan. Hampir 100\% responden setuju dan sangat setuju terhadap aspek ada kepastian tindaklanjut atas penanganan pengaduan. Dari sejumlah 37 responden yang menyatakan pernah melakukan pengaduan, hampir $100 \%$ responden setuju dan sangat setuju terhadap aspek tidak ada diskriminasi dalam penanganan pengaduan. Produk/jasalayanan yang diterima sesuai dengan daftar produk/ jasa layanan yang tersedia. Dari sejumlah 37 responden yang menyatakan pernah melakukan pengaduan, $100 \%$ responden setuju dan sangat setuju terhadap aspek produk/jasa layanan yang diterima sesuai dengan daftar produk jasa layanan.

\section{Pembahasan}

Pada penelitian ini data persepsi diukur dengan menggunakan skala penilaian antara 1-4. Nilai 1 merupakan skor persepsi paling rendah, dan nilai 4 merupakan skor persepsi paling tinggi dan mencerminkan kualitas birokrasi yang bersih dan baik dalam melayani (Menpan RB, 2017). Perhitungan IPK dari Survei IPK Layanan BLA Semarang 2020 disajikan dalam bentuk skoring/angka absolute berada pada skala 1-4. Teknik analisis perhitungan IPK pada kuesioner sebagai berikut:

Pertama, setiap unsure penilaian persepsi terdiri atas 4 pilihan dengan konversi nilai 1, 2, 3, dan 4. Kedua, jumlah nilai total persepsi korupsi per unsure dijumlahkan dan dianalisis sebagai Indeks Persepsi Korupsi sebagai berikut:

IPKTiapKategori $=\frac{\text { JumlahNilaiPersepsiTiapKategori }}{\text { Banyaknyaitemtiapunsur }}$

Ketiga, menghitung IPK dengan

menggunakan rumus sebagai berikut:

$$
I P K=\frac{\text { JumlahNilaiPersepsiTiapKategori }}{\text { BanyaknyaKategori }}
$$

Skala indeks korupsi antara 0-4. Semakin mendekati skor 4 artinya persepsi anti korupsi semakin baik.

\section{IPK Kategori A.}

Tabel 2. PersyaratanPelayanan

\begin{tabular}{llc} 
No. & Aspek yang Diteliti/Pertanyaan & IPK \\
\hline 1 & Informasi tentang persyaratanpelayanan & 3,306 \\
\hline 2 & $\begin{array}{l}\text { Pemenuhandokumenpersyaratanpelayanan } \\
\text { yang harusdisiapkan }\end{array}$ & 3,250 \\
\hline & $\begin{array}{l}\text { JumlahIndeksPersepsiKorupsi } \\
\text { JumlahAspek }\end{array}$ & 6,556 \\
\hline & 2
\end{tabular}


Indeks Persepsi Korupsi Kategori

IPK Persyaratan Pelayanan adalah

\section{IPKKategoriPersyaratanPelayanan $=$ $\frac{6,556}{2}$}

$=3,278$

2. IPK Kategori B.

Dari tabel 3. IPK Kategori Prosedur Pelayanan dapat dihitung sebagai berikut;

$$
\begin{aligned}
& \text { IPKKategoriProsedurPelayanan }= \\
& \frac{13,042}{4} \\
& =3,260
\end{aligned}
$$

\begin{tabular}{|c|c|c|}
\hline No. & Aspek yang Diteliti/Pertanyaan & IPK \\
\hline 3 & Informasialurpelayanan & 3,278 \\
\hline 4 & Pemenuhanprosedur/alurpelayanan & 3,236 \\
\hline II.1 & $\begin{array}{l}\text { Prosedurpelayanan yang } \\
\text { ditetapkansudahmemadai dan } \\
\text { tidakberpotensimenimbulkankorupsi, } \\
\text { kolusi, dan nepotisme (KKN) }\end{array}$ & 3,333 \\
\hline II. 2 & $\begin{array}{l}\text { Petugaspelayanantidakmemberikanpelay } \\
\text { anan di luarprosedur yang } \\
\text { telahditetapkandenganimbalan } \\
\text { uang/barang }\end{array}$ & 3,194 \\
\hline & JumlahIndeksPersepsiKorupsi & 13,042 \\
\hline
\end{tabular}

\section{Tabel 3. ProsedurPelayanan}

\section{IPK Kategori C.}

Berikut ini adalah hasil perhitungan IPK Waktu Pelayanan.

\section{Tabel 4. Waktu Layanan}

\begin{tabular}{llc}
\hline No. & Aspek yang Diteliti/Pertanyaan & IPK \\
\hline 5 & Informasiwaktuoperasionalpelayanan & 3,361 \\
\hline & $\begin{array}{l}\text { Pelayanandiberikansesuaidenganwaktuoperasional } \\
\text { yang ditetapkan }\end{array}$ & 3,208 \\
\hline & JumlahIndeksPersepsiKorupsi & 6,569 \\
\hline & JumlahAspek & 2 \\
\hline
\end{tabular}

IPK Waktu Pelayanan adalah

$$
\begin{aligned}
& \text { IPKKategoriWaktuPelayanan }=\frac{6,569}{2} \\
& =3,285
\end{aligned}
$$

4. IPK Kategori D.

Dari tabel 5. diperoleh hasil perhitungan IPK Biaya dan Tarif. IPK Kategori Produk/ Jasa Spesifikasi Jenis Layanan

$$
\begin{aligned}
& \text { IPKKategoriSpesifikasiJenisLayanan }= \\
& \frac{6,514}{2} \\
& =3,257
\end{aligned}
$$

Tabel. 5. Biaya dan Tarif

\begin{tabular}{llc}
\hline No. & Aspek yang Diteliti/Pertanyaan & IPK \\
\hline 7 & Informasitentangpersyaratanpelayanan & 3,194 \\
\hline \multirow{2}{*}{ II.3 } & $\begin{array}{l}\text { Tidakterdapatpraktikpercaloan/perantara } \\
\text { yang tidakresmi }\end{array}$ & 3,347 \\
\hline \multirow{2}{*}{ II.5 } & Tidakterdapatpungutan liar & 3,389 \\
\hline & JumlahIndeksPersepsiKorupsi & 9,931 \\
\hline & JumlahAspek & 3
\end{tabular}

IPK Kategori Biaya dan Tarif adalah

IPKKategoriBiayadanTarif $=\frac{9,931}{3}$

$=3,310$

5. IPKKategori E.

Berikut ini adalah hasil perhitungan

IPK Kategori E (Produk/Jasa

Spesifikasi Jenis Layanan)

Tabel 6. Produk/Jasa Spesifikasi Jenis Layanan

\begin{tabular}{ccc}
\hline & Aspek yang Diteliti/Pertanyaan & IPK \\
\hline No. & Informasitentang daftar produk/jasalayanan & 3,236 \\
\hline 9 & Kemudahanaksesseluruhproduk/jasalayanan & 3,278 \\
\hline & JumlahIndeksPersepsiKorupsi & 6,514 \\
\hline & JumlahAspek & 2 \\
\hline
\end{tabular}


IPK Kategori Produk/ Jasa Spesifikasi Jenis Layanan

\section{IPKKategoriSpesifikasiJenisLayanan $=$ $=3,257^{\frac{6,514}{2}}$}

6. Kategori F :

Berikut ini adalah hasil perhitungan IPK F (Kompetensi Petugas Pelaksana dan Keandalan Sistem).IPK

\section{Tabel.7.Kompetensi Petugas Pelaksana dan Keandalan Sistem}

\begin{tabular}{llc}
\hline No. & Aspek yang Diteliti/Pertanyaan & IPK \\
\hline 10 & Kompetensipetugaspelayanan & 3,333 \\
\hline 11 & Petugaspelayananbertanggungjawab & 3,375 \\
\hline 12 & Keandalanaplikasi/sistempelayanan & 3,278 \\
\hline II.4 & Petugaspelayanantidakdeskriminatif & 3,236 \\
\hline & $\begin{array}{l}\text { Petugaspelayananmenolakpemberian } \\
\text { uang/barangterkaitpelayanan yang } \\
\text { diberikan }\end{array}$ & 3,236 \\
\hline
\end{tabular}

KategoriKompetensiPetugasPelaksana dan Keandalan Sistem

\section{IPKKategoriKompetensiPetugasPelaksana}

$$
\text { danKeandalanSistem }=\frac{16,458}{5}
$$

$=3,292$

7. IPK Kategori G Berikut ini adalah hasil perhitungan IPK Layanan Petugas Memberikan Solusi.
Tabel. 8. Layanan Petugas Memberikan Solusi.

\begin{tabular}{|c|c|c|}
\hline No, & Asgek yangDiteliti/P ertanyaan & IPK \\
\hline 13 & $\begin{array}{l}\text { Petupas pelayaman memb erikan solusi kepada pengenua apabila } \\
\text { ada permaslahan }\end{array}$ & 3,083 \\
\hline 14 & Kecepatanpetupgspelayanandalammemberikansolusipermasclakm & 3,278 \\
\hline & JumlahIndeks $P$ erseg sikormpgi & 6,361 \\
\hline & JumlahAsgek & 2 \\
\hline
\end{tabular}

IPK Kategori Layanan Petugas

Memberikan Solusi

IPKKategoriLayananPetugasMemberikanSolusi = $\frac{6,361}{2}$

$=3,181$

8. IPK Kategori $\mathrm{H}$

Berikut ini adalah hasil perhitungan

IPK Kategori Penanganan Pengaduan,

Saran, dan Masuk

Tabel.9.Penanganan Pengaduan, Saran, dan Masukan

\begin{tabular}{|c|c|c|}
\hline No. & Aspek yang Diteliti/Pertanyaan & IPK \\
\hline 15 & $\begin{array}{l}\text { Kemudahan akses fasilitas pengaduan (tempat } \\
\text { pengaduan/hotline/callcenter) }\end{array}$ & 3,139 \\
\hline 16 & Prosedur pengaduan mudah dilaksanakan & 3,222 \\
\hline 17 & $\begin{array}{l}\text { Petugas pelayanan pengaduan dapat } \\
\text { memberikan solusi kepada pelaporan pabila } \\
\text { ada permasalahan }\end{array}$ & 3,690 \\
\hline 18 & $\begin{array}{l}\text { Ada kepastian tindaklanjut atas penanganan } \\
\text { pengaduan }\end{array}$ & 3,714 \\
\hline II.7 & $\begin{array}{l}\text { Tidak ada diskriminasi dalam penanganan } \\
\text { pengaduan }\end{array}$ & 3,048 \\
\hline
\end{tabular}

IPK Kategori Penanganan Pengaduan, Saran, dan Masukan

IPKKategoriPenangananPengaduan, Saran, danMasukan $=\frac{19,861}{6}$ $=3,310$ 
Berdasarkan perhitungan di atas, IPK per Kategori sebagaimana dapat dilihat dalam tabel 9, berikut ini;

Tabel.9. IPK per Kategori

\begin{tabular}{clc}
\hline No. & \multicolumn{1}{c}{ Kategori } & IPK \\
\hline A & PersyaratanPelayanan & 3,278 \\
\hline B & ProsedurPelayanan & 3,260 \\
\hline C & Waktu Pelayanan & 3,285 \\
\hline D & Biaya dan Tarif & 3,310 \\
\hline E & Produk/ Jasa SpesifikasiJenisLayanan & 3,257 \\
\hline F & KompetensiPetugasPelaksana dan & 3,292 \\
& KeandalanSistem & \\
\hline G & LayananPetugasMemberikan Solusi & 3,181 \\
\hline H & PenangananPengaduan, Saran, dan Masukan & 3,310 \\
\hline & $\quad$ Jumlah & 26,173
\end{tabular}

Perhitungan IPK Layanan Balai Litbang Agama Semarang Tahun 2020 adalah

$$
I P K=\frac{26,1730}{8}=3,2716
$$

Dari hasil perhitungan IPK tersebut maka masing-masing kategori disajikan pada Grafik.1.sebagai berikut;

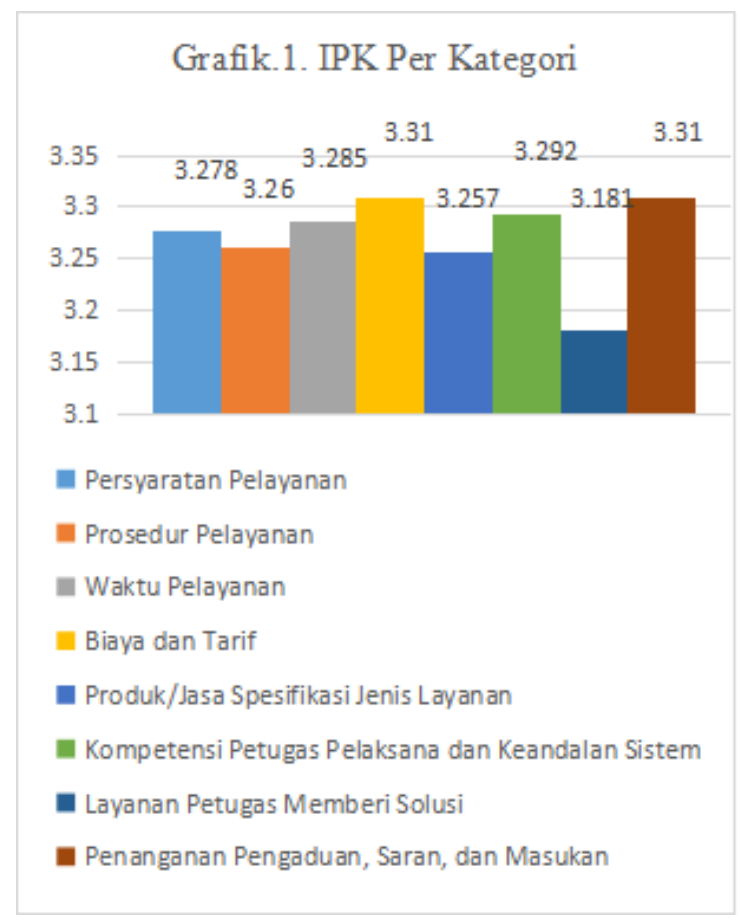

Grafik.1. IPK Per Kategori
Berdasarkan grafik 1. Tersebut dapat dijelaskan bahwa IPK Layanan BLA Semarang dari aspek layanan maka penanganan pengaduan, saran dan masukan serta biaya dan tariff dalam pelayanan memiliki nilai tertinggi yaitu 3,331. Sebaliknya layanan petugas memberikan solusi menempati peringkat terendah yaitu 3,181 pada skala 4 . Sementara untuk aspek yang lainnya diperoleh nilai rata - rata mendekati 3,3 pada beberapa aspek sebagai berikut; persyaratan layanan, prosedur pelayanan, waktu pelayanan, produk/jasa spesifikasi layanan, kompetensi petugas pelaksana dan keandalan sistem. Secara keseluruhan BLA Semarang Tahun 2020 memiliki Indeks Persepsi Korupsi Kepuasan Layanan sebesar 3,3 pada skala 4 dengan kategori baik.

\section{PENUTUP}

\section{Simpulan}

Berdasarkan data temuan dan pembahasan diatas, maka dari hasil penelitian ini dapat disimpulkan bahwa Indeks Persepsi Korupsi Kepuasan Layanan Balai Litbang Agama Semarang tahun 2020 diperoleh nilai sebesar 3,31 dalam skala 4. Hasil tersebut diperoleh dari kategori layanan dimana penanganan pengaduan, saran dan masukan serta biaya dan tarif dalam pelayanan memiliki nilai tertinggi yaitu 3,331. Sebaliknya kategori layanan petugas dalam memberikan solusi menempati peringkat terendah yaitu 3,181 pada skala 4. IPK Layanan Balai Litbang Agama Semarang Tahun 2020 adalah = 3,2716. Secara keseluruhan hasil penelitian ini diperoleh hasil indeks persepsi korupsi sebesar 3,27 dan indeks kepuasan layanan 3,18 dalam skala 4 .

\section{Saran}

Dari hasil penelitian ini maka penulis memberikan masukan dan saran pelayanan yang dilakukan oleh ASN Kementreian Agama pada umumnya dan 
secara khusus untuk BLA Semarang, hal hal sebagai berikut;

1. Kementerian Agama agar dapat memberikan sosialisasi berkaitan dengan Indeks Pesepsi Korupsi dan Kepuasan layanan kepada UPT- UPT yang ada karena Indeks Persepsi Korupsi merupakan salah satu aspek yang penting dalam penilaian Zona Integritas oleh Menpan RB dalam rangka mewujudkan Reformasi Birokrasi dalam membangun Zona Integritas menuju WBK - WBBM.

2. Kompetensi SDM Balai Litbang Agama Semarang agar dapat ditingkatkan terutama dalam memberikan kepuasan layanan terhadap stakeholder yang dilayani baik internal maupun eksternal sesuai dengan tugas dan fungsi BLA Semarang.

3. Kepala BLA Semarang agar dapat memberikan bimbingan kepada pegawai BLA Semarang khususnya pada aspek layanan petugas dalam memberikan solusi masalah yang dihadapi pengguna layanan.

4. Balai Litbang Agama Semarang perlu melakukan penelitian lebih lanjut berkaitan dengan layanan yang diberikan kepada masyarakat.

\section{DAFTAR PUSTAKA}

Anonim. (2020). Modul Materi Tindak Pidana Korupsi. diambil dari https://docplayer.info/153276149-Modul-materi-tindak-pidanakorupsi.html.tanggal 20 April 2021.

Badan Litbang dan Diklat. (2020). Perjanjian Kinerja Kepala Balai Litbang Agama Semarang Tahun Anggaran 2020. Jakarta Indonesia.

Hariyanto, I. (2020). KPK : Indeks Persepsi Korupsi Indonesia 40, Kalah dari Malaysia Singapura. Dipetik Januari 20, 2021 dari https://news.detik.com/berita/d5005012/kpk-indeks-persepsi-korupsi-indonesia-40-kalah-dari-malaysiasingapura.

Kementerian Pendayagunaan Aparatur Negara dan Reformasi Birokrasi. (2017). Peraturan Menteri Pendayagunaan Aparatur Negara Dan Reformasi Birokrasi Republik Indonesia Nomor 14 Tahun 2017 tentang Pedoman Penyusunan Survei Kepuasan Masyarakat Unit Penyelenggara Pelayanan Publik. Jakarta, Indonesia

Manaf, Abdul. (2016), Modul Materi Good Governance Dan Pelayanan Publik. Direktorat Pendidikan dan Pelayanan Masyarakat Kedeputian Bidang Pencegahan Komisi Pemberantasan Korupsi. PT. Multi Area Desentralisasi Pembangunan (MADEP).

Nasution. (2011). Metode Research (Penelitian Ilmiah). PT. Bumi Aksara, Jakarta

Nasir Moh. (2003). Metode Penelitian. Ghalia Indonesia Jakarta

Sasongko, F dan Subagio, H. (2013). Pengaruh Kualitas Layanan Terhadap Kepuasan Pelanggan Restoran Ayam Penyet. Jurnal Manajemen Pemasaran Petra Vol. 1, No. 2, (2013) 1-7. 
Setiawan P. (2020). Pengertian Distribusi Frekuensi Terlengkap. diambil Pebruari 19, 2021 dari https://www.gurupendidikan.co.id/distribusi-frekuensi/

Transparancy International. (2020). Corruption Perceptions Index. Dipetik Maret 18, 2021 dari https://www.transparency.org/en/cpi/2020/index/idn\#

Undang - Undang RI Nomor 25 Tahun 2009 tentang Pelayanan Publik Jakarta 